\title{
Identification of miR-26 as a key mediator of estrogen stimulated cell proliferation by targeting CHD1, GREB1 and KPNA2
}

Sheng $\operatorname{Tan}^{1 \dagger}{ }^{1}$, Keshuo Ding ${ }^{1 \dagger}$, Rui Li ${ }^{1}$, Weijie Zhang ${ }^{1}$, Gaopeng Li ${ }^{1}$, Xiangjun Kong ${ }^{1}$, Pengxu Qian ${ }^{1}$, Peter E Lobie ${ }^{2,3^{*}}$ and Tao Zhu ${ }^{1,4^{*}}$

\begin{abstract}
Introduction: Estrogen signaling is pivotal in the progression of estrogen receptor positive breast cancer primarily by the regulation of cell survival and proliferation. Micro (mi)RNAs have been demonstrated to be regulated by estrogen to mediate estrogenic effects. Herein, we determined the role of estrogen regulated miR-26 and its underlying molecular mechanisms associated with estrogen receptor (ER)+ breast cancer proliferation.

Methods: The expression of miR-26a and miR-26b was evaluated by real-time quantitative (RT)-PCR. The expression of miR-26a or miR-26b was modulated in ER+ breast cancer cells (MCF-7 and T47D) and tumor cell growth in vitro and an in vivo xenograft model was determined. Bioinformatics analyses were utilized to screen for estrogen responsive genes, which were also predicted to be targeted by miR-26. Luciferase reporter assays were performed to confirm miR-26 regulation of the 3' UTR of target genes. The levels of miR-26 target genes (CHD1, GREB1 and KPNA2) were evaluated by western blotting and immunohistochemistry.

Results: Estrogen reduced the expression of miR-26a and miR-26b in ER+ breast cancer cells. Forced expression of miR-26a or miR-26b significantly inhibited the estrogen stimulated growth of ER+ breast cancer cells and tumor growth in xenograft models, whereas miR-26a/b depletion increased the growth of ER+ breast cancer cells in the absence of estrogen treatment. Screening of estrogen responsive genes, which were also predicted to be targeted by miR-26, identified GREB1 and nine other genes (AGPAT5, AMMECR1, CHD1, ERLIN1, HSPA8, KPNA2, MREG, NARG1, and PLOD2). Further verification has identified nine genes (AGPAT5, CHD1, ERLIN1, GREB1, HSPA8, KPNA2, MREG, NARG1 and PLOD2) which were directly targeted by miR-26 via their 3' UTR. Functional screening suggested only three estrogen regulated miR-26 target genes (CHD1, GREB1 and KPNA2) were involved in the regulation of estrogen promoted cell proliferation. Depletion of either CHD1, GREB1 or KPNA2 significantly abrogated the enhanced growth of ER+ breast cancer cells due to miR-26 depletion. We further demonstrated that estrogen stimulated c-MYC expression was both sufficient and necessary for the diminished expression of miR-26a and miR-26b.
\end{abstract}

Conclusions: We have identified a novel estrogen/MYC/miR-26 axis that mediates estrogen stimulated cell growth via CHD1, GREB1 and KPNA2.

\footnotetext{
*Correspondence: csipel@nus.edu.sg; zhut@ustc.edu.cn

${ }^{\dagger}$ Equal contributors

${ }^{2}$ Cancer Science Institute of Singapore, National University of Singapore,

Centre for Translational Medicine MD6, \#11-01 K, 14 Medical Drive, Singapore

117599, Singapore

'Laboratory of Molecular Tumor Pathology, School of Life Sciences,

University of Science and Technology of China, Hefei 230027, China

Full list of author information is available at the end of the article
}

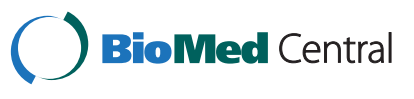

(c) 2014 Tan et al.; licensee BioMed Central Ltd. This is an Open Access article distributed under the terms of the Creative Commons Attribution License (http://creativecommons.org/licenses/by/2.0), which permits unrestricted use, distribution, and reproduction in any medium, provided the original work is properly credited. The Creative Commons Public Domain Dedication waiver (http://creativecommons.org/publicdomain/zero/1.0/) applies to the data made available in this article, unless otherwise stated. 


\section{Introduction}

Breast cancer is the most common malignant disease in women. However, the molecular pathogenesis of breast cancer remains poorly defined due to its heterogeneity [1]. Approximately $70 \%$ of human breast cancer is estrogen receptor (ER)-alpha-positive and estrogen signaling plays a pivotal role in both the pathogenesis and the progression of ER+ breast cancer [2]. One of pathological effects of estrogen in hormone-responsive breast cancer is to promote proliferation and tumor growth [3]. In postmenopausal women with early-stage ER+ breast cancer, anti-estrogen therapy is utilized as an effective adjuvant treatment. However, many patients whose tumors respond to anti-estrogen therapy eventually develop resistance and tumor recurrence [4]. An improved understanding of the molecular basis of estrogen action and the development of new strategies to improve the efficacy of anti-estrogens are therefore required.

MicroRNAs (miRNAs) are noncoding RNAs that range in size from 20 to 25 nucleotides and promote mRNA degradation and/or inhibition of translation by base pairing with the 3' untranslated region (UTR) of target mRNAs [5]. Multiple recent reports have established miRNAs as important for the initiation, promotion and progression of various human cancers [6,7]. miRNAs have been identified to function in both oncogenic and tumor suppresser roles [6,7]. The therapeutic manipulation of miRNAs may present an attractive clinical strategy because one miRNA could potentially regulate the coordinated expression of hundreds of different genes [8,9]. Various recent reports have observed that miRNAs are often deregulated in breast cancer $[10,11]$ and that several deregulated miRNAs (for example, let-7, miR-21, miR$125 \mathrm{~b}, \mathrm{miR}-221$ and miR-222) may possess important roles in breast cancer progression by contributing to cell proliferation, survival and metastasis [12-17]. The expression of some miRNAs has also been demonstrated to be regulated by estrogen in an ER-dependent manner [18-20]. The identification of the targets of estrogen-regulated miRNAs is critical to understand function of the miRNAs and their underlying molecular mechanisms associated with ER+ breast cancer progression.

In this study, we report that the expression of miR-26a and miR-26b was decreased by estrogen stimulation and that forced expression of miR-26a or miR-26b abrogated estrogen-stimulated breast cancer cell growth both in vitro and in vivo. CHD1, GREB1 and KPNA2 were identified as estrogen-regulated direct targets of miR-26a/b. The expression of CHD1, GREB1 or KPNA2 was required for estrogen-stimulated breast cancer cell growth. We further demonstrated that estrogen-regulated c-MYC expression was required for the suppression of miR-26a and miR-26b levels. Methods to enhance miR-26 expression may thus be considered as an adjuvant therapeutic strategy for patients with ER + breast cancer.

\section{Methods}

\section{Cell culture}

MCF-7, T47D, MDA-MB-231 and BT549 cells were purchased from American Type Culture Collection and were cultured in the recommended conditions. All cells were maintained in a humidified incubator at $37^{\circ} \mathrm{C}$ and $5 \%$ carbon dioxide. For $17 \beta$-estradiol (E2) stimulation experiments, cells were cultured for at least 3 days in phenol red-free RPMI 1640 with 5\% dextran-coated charcoal-treated serum before E2 $\left(10^{-8} \mathrm{~mol} / \mathrm{l}\right)$ treatment.

\section{Plasmid construction}

To stably express miR-26a or miR-26b in MCF-7 cells, the retroviral vector pBABE-Puro-miR-26a or pBABEPuro-miR-26b was constructed. The genome segment encompassing the mature miR-26a sequence was as described previously [21] or the 77 base pair DNA fragment corresponding to pre-miR-26b was amplified from human genomic DNA and then cloned into the pBABEPuro plasmid. To stably deplete miR-26a or miR-26b in MCF-7 and T47D cells, we generated miR-26a and miR$26 \mathrm{~b}$ sponge elements. We introduced nine copies of CCTATCCACCATTACTTGAA complementary sequences to miR-26a and miR-26b, each with mismatches at positions 11 to 13 for improved stability, into pBABE-Puro expression vector $[22,23]$.

\section{RNA oligonucleotides and transfection}

miRNAs and small interfering RNAs (siRNAs) were synthesized by GenePharma (Shanghai, China). miRNA mimics are synthetic duplexes representing mature miRNAs. siRNA and miRNA transfection was performed using lip2000 (QIAGEN). $20 \mathrm{nmol} / \mathrm{l}$ siRNA or miRNA was used for transfection in serum-free medium. Total RNA and protein were prepared 48 to 72 hours after transfection and further used for quantitative polymerase chain reaction (PCR) or western blot analysis.

\section{Quantitative analysis of miRNAs and mRNAs}

Total RNA and miRNA were extracted from cultured cells or clinical samples of breast cancer using the miRVana miRNA Isolation Kit (Ambion) according to the manufacturer's protocols. The TaqMan stem-loop realtime (RT)-PCR approach was used to assess the expression of miRNAs with kits from Applied Biosystems. For quantitative analysis of mRNA expression, 100 to $200 \mathrm{ng}$ total RNA was used for synthesis of random-primed single-stranded cDNA using the Primescript RT reagent kit (TaKaRa) and cDNA was subjected to quantitative PCR using SYBR green Master MIX (Applied Biosystem). The relative amount of gene transcripts were normalized 
to glyceraldehyde 3-phosphate dehydrogenase. Three independent experiments were each performed in triplicate.

\section{Protein extraction and western blot}

Cells were lysed using cell lysis buffer (Cell Signaling) and a protein concentration determined with the BCA Protein Assay kit (Pierce). Equal amounts of total proteins were separated in 10\% SDS polyacrylamide gels and transferred to polyvinylidene difluoride membranes (Bio-Rad). Membranes were blocked for 1 hour with 1\% bovine serum albumin in Tris-buffered saline containing $0.05 \%$ Tween 20 , incubated overnight with primary antibody, washed and incubated with secondary antibody, and visualized by chemiluminescence. The antibodies used were as follows: CHD1 (Millipore), GREB1 (Abcam), KPNA2 (Abcam) and $\beta$-actin (Abcam).

\section{Luciferase reporter assay}

The full-length 3' UTR of the genes were amplified and cloned downstream of Renilla luciferase in a psiCHECK2 vector (Promega). Cells plated on 24-well plates were transfected with $100 \mathrm{ng}$ plasmid and $200 \mathrm{nmol} / \mathrm{l} \mathrm{miR-26a}$, miR-26b mimics or negative control. After 48 hours, cells were lysed and assayed with Dual Luciferase Assay (Promega) according to the manufacturer's instructions. Three independent experiments were performed in triplicate.

\section{MTT assay}

Cells $\left(10^{3}\right.$ per well) were plated in 96 -well plates in a final volume of $100 \mu \mathrm{l}$. Twenty-four hours after plating, 10 pmol miRNA mimics, siRNAs or negative control oligonucleotides were transfected into the cells with lip2000 (QIAGEN). The MTT assay was performed at 24, 48, 72 and 96 hours as described previously [24].

\section{Tumor xenograft in nude mice}

MCF-7-NC, MCF-7-miR-26a or MCF-7-miR-26b cells $\left(3 \times 10^{6}\right.$ cells per site $)$ were injected into the mammary fat pad of 4-week-old BALBc nu/nu mice (Shanghai Slaccas). Long-release E2 pellets (Innovative Research of America) were implanted the day before inoculation.

\section{In vivo protocol approval}

Research protocols were designed and conducted in accordance with the guidelines set by the Institutional Animal Care and Use Committee, University of Science and Technology of China (USTCACUC1301016).

\section{Results}

Decreased expression of miR-26 is required for estrogenpromoted cell proliferation

We have previously screened estrogen-regulated miRNAs using miRNA microarray profiling [17]. In addition to let$7 \mathrm{~g}$, which was downregulated by estrogen, miR-26a and
miR-26b were among other estrogen-regulated miRNAs in ER-alpha-positive MCF-7 cells (Figure S1 in Additional file 1). ER+ MCF-7 and T47D breast cancer cells were used to verify estrogen regulation of miR-26a and miR26b expression using TaqMan stem-loop RT-PCR analysis. The miRNA expression values were normalized to U6. The expression of miR-26a and miR-26b significantly decreased after both 12 and 24 hours treatment with $10^{-8} \mathrm{~mol} / \mathrm{l} \mathrm{E2}$ in MCF-7 and T47D cells with prior estrogen deprivation (Figure 1a,b).

We next determined whether miR-26a/b modulated growth of ER+ breast cancer cells. MCF-7 and T47D cells were thus transfected with negative control, miR$26 \mathrm{a}$ mimics or miR-26b mimics. Forced expression of miR-26a or miR-26b inhibited the estrogen-simulated increase in cell viability and total cell number in MCF-7 (Figure 1c,d) and T47D cells (Figure S2 in Additional file 1) when compared with control oligonucleotides. However, forced expression of miR-26a or miR-26b did not significantly affect either cell viability or total cell number in both types of cells when cultured in estrogen-deprived conditions (Figure 1c,d; Figure S2 in Additional file 1) compared with control oligonucleotides. Moreover, forced expression of miR-26a or miR-26b did not significantly affect either cell viability or total cell number of the ER-negative MDA-MB231 and BT549 cell lines (Figure S2 in Additional file 1). Hence it is apparent that forced expression of miR-26a or miR-26b abrogated the proliferative effects of E2 in ER+ breast cancer cells.

We further constructed a miR-26a and miR-26b dual specific sponge, namely Sponge-miR-26, to deplete both endogenous miR-26a and miR-26b (Figure 1e) and to determine whether reduced $\mathrm{miR}-26 \mathrm{a} / \mathrm{b}$ levels were required for estrogen promotion of mammary carcinoma cell proliferation. MCF-7-Sponge-miR-26 and T47D-SpongemiR-26 as well as their respective control cells (MCF-7-Vec and T47D-Vec) were generated by forced expression of Sponge-miR-26 or empty vector. Forced expression of Sponge-miR-26 significantly reduced the expression of both miR-26a and miR-26b (Figure 1f,g). miR-26 depletion in MCF-7 and T47D cells resulted in increased cell growth under estrogen-deprived conditions (Figure 1h,i; Figure S2 in Additional file 1). However, no significant differences in estrogen-simulated cell viability or total cell number were observed upon miR-26 depletion in those ER+ cells. Hence, it is apparent that estrogen repression of miR-26 expression is required for estrogenic effects in ER+ breast cancer cells.

\section{miR-26 expression suppressed breast cancer growth in nude mice}

We further determined whether miRNA-26 expression could suppress breast cancer cell growth in vivo. MCF7-miR-26a, MCF-7-miR-26b and cognate control cells were injected subcutaneously into female BALB/c nude 


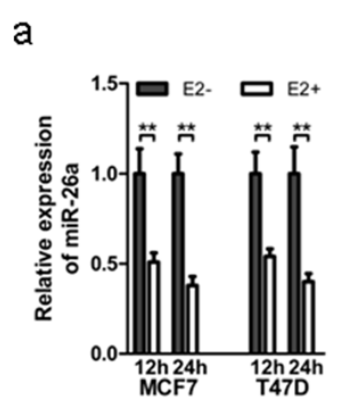

b

d

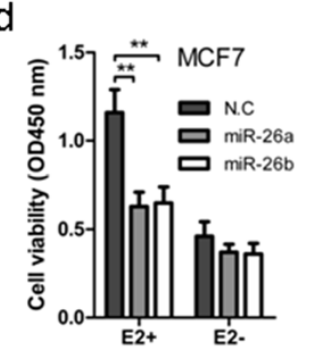

g

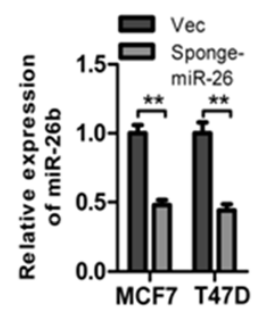

e
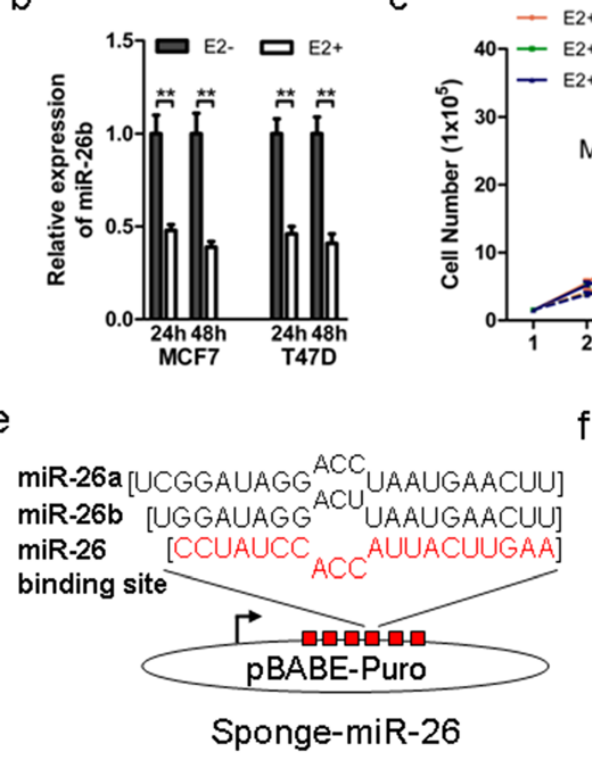

$\mathrm{h}$

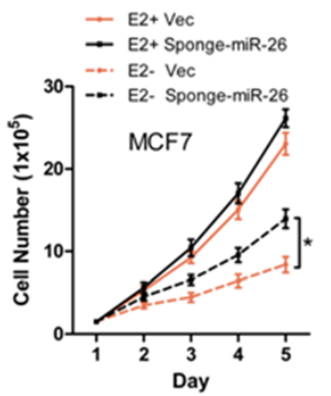

C

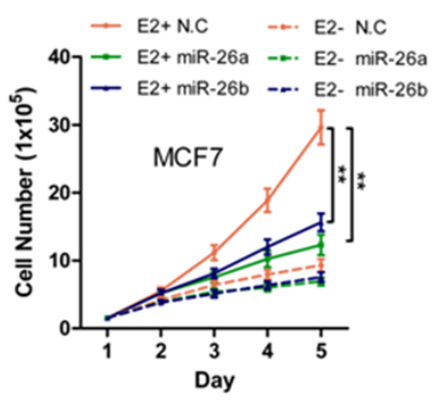

f

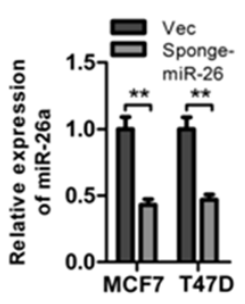

i

MCF7

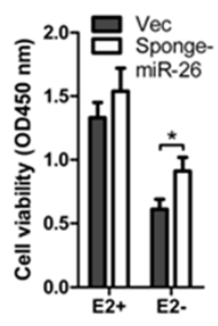

Figure 1 miR-26 inhibits breast cancer cell growth. (a, b) Effect of 17ß-estradiol (E2) on miR-26a and miR-26b expression. MCF-7 and T47D were treated with $10 \mathrm{nmol} / \mathrm{I}$ E2 in phenol red-free medium containing 5\% charcoal-stripped fetal bovine serum and microRNAs (miRNAs) from a triplicate sample were isolated at indicated time points. The miRNA level was measured by TaqMan stem-loop quantitative real-time polymerase chain reaction (qRT-PCR). U6 was used as an internal control. Relative expression level of (a) miR-26a and (b) miR-26b. (c) MCF-7 cells after 2 days of E2 deprivation were transfected with NC, miR-26a or miR-26b mimics and 1 day later were seeded in six-well plates with or without $10 \mathrm{nmol} / \mathrm{l}$ E2. At the indicated time points after transfection, cells were trypsinized and total cell numbers were counted using Trypan blue. (d) MCF-7 cells after 2 days of E2 deprival were transfected with NC, miR-26a or miR-26b mimics and 1 day later were seeded in 96-well plates with or without $10 \mathrm{nmol} / \mathrm{I}$ E2. At 72 hours after plating, the MTT assay was performed to determine the proliferation (viability) of MCF-7 cells. (e) Sequences of mature miR-26a/b, and one repeat of sponge. (f, $\mathbf{g})$ Relative expression levels of miR-26a and miR-26b between MCF-7-Vec, MCF-7-Sponge-miR-26 or T47D-Vec, T47D-Sponge-miR-26 were measured by TaqMan stem-loop qRT-PCR. (h) MCF-7-Vec and MCF-7-Sponge-miR-26 cells after 3 days of E2 deprivation were seeded in six-well plates with or without $10 \mathrm{nmol} / \mathrm{I} \mathrm{E2}$. At the indicated time points, MCF-7-Vec and MCF-7-Sponge-miR-26 cells were trypsinized and total cell numbers were counted using Trypan blue. (i) MCF-7-Vec and MCF-7-Sponge-miR-26 cells after 3 days of E2 deprivation were seeded in 96-well plates with or without $10 \mathrm{nmol} / \mathrm{I} \mathrm{E2}$. At 96 hours after plating, the MTT assay was performed to determine the proliferation of MCF-7-Vec and MCF-7-Sponge-miR-26 cells. ${ }^{*} P<0.05 .{ }^{*} P<0.01$.

mice in the presence of exogenous estrogen supplementation. Inoculation of MCF-7-miR-26a or MCF-7-miR$26 \mathrm{~b}$ cells resulted in the formation of slower growing and significantly smaller tumors compared with tumors derived from MCF-7-NC inoculated mice (Figure 2a). The miR-26a and miR-26b expression levels were quantified in tumors derived from MCF-7-miR-26a or MCF-7-miR-26b cells (Figure 2b,c). A significantly lower proportion of proliferative Ki67+ tumor cells were observed by immunohistochemical analysis in tumor sections derived from MCF-7-miR-26a or
MCF-7-miR-26b cells compared with the control cells (Figure 2d).

\section{Identification of targets of miR-26 involved in estrogen-promoted cell growth}

To identify downstream targets of miR-26, we performed bioinformatics analysis using three algorithms that predict the mRNA targets of a particular miRNA: TargetScan, PicTar and miRanda. A total of 695 putative target genes of miR-26 were predicted by at least one of the three algorithms (Figure 3a). Four independent gene 


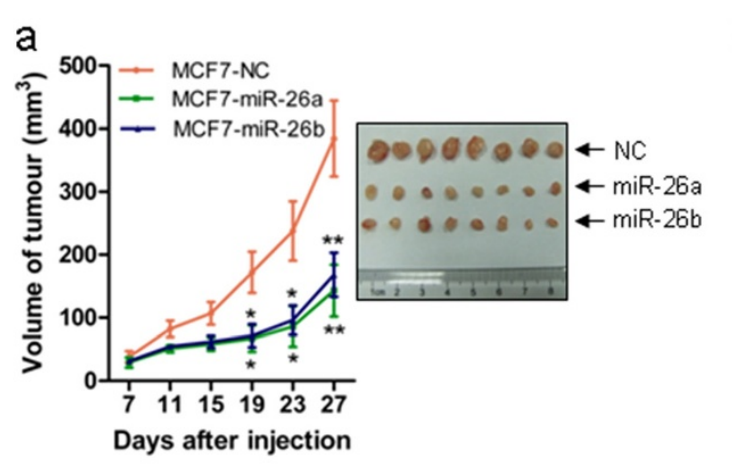

b

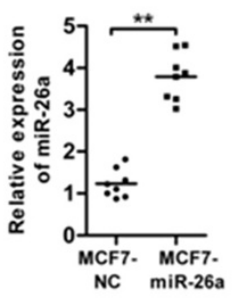

C

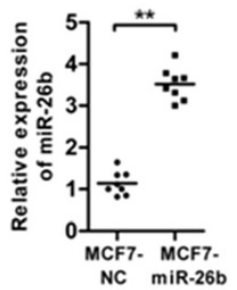

d
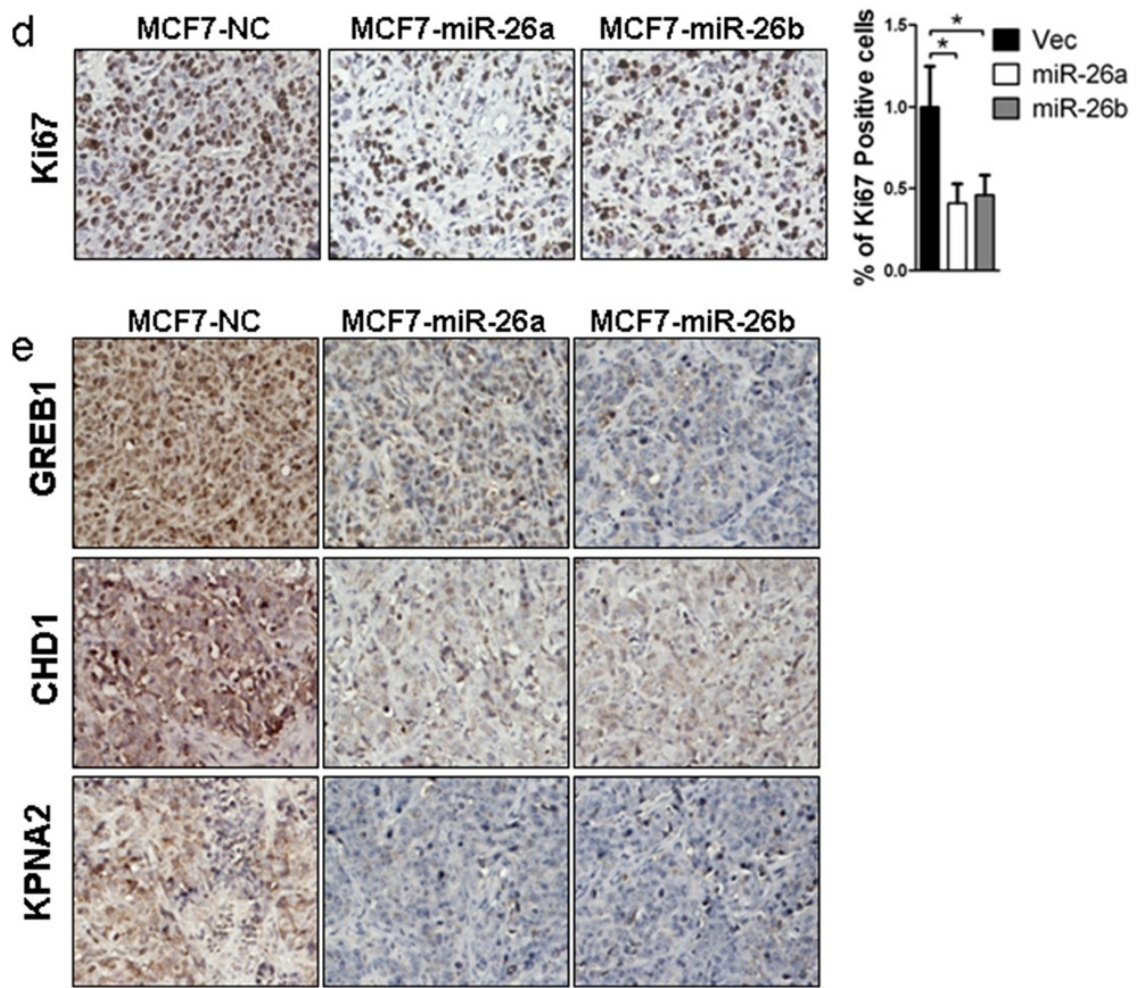

Figure 2 miR-26 inhibits breast tumor growth in vivo. (a) MCF-7-NC, MCF-7-miR-26a and MCF-7-miR-26b cells mixed with matrigel were transplanted into the mammary fat pad of immunodeficient mice supplemented with 17ß-estradiol (E2), and tumor sizes were measured every 4 days until day 27 and the tumors were harvested. (b, $\mathbf{c})$ The relative expression levels of miR-26a/b between tumors derived from MCF-7-NC and tumors generated from MCF-7-miR-26a respectively were quantified by TaqMan stem-loop quantitative real-time polymerase chain reaction. U6 was used as an internal control. (d) Tumors derived from MCF-7-miR-26a/b cells showed a lower level of Ki-67 protein than tumors derived from MCF-7-NC cells. (e) Immunohistochemistry analysis of GREB1, CHD1 and KPNA2 expression for tumor sections. ${ }^{*} P<0.05$. ${ }^{* *} P<0.01$.

expression datasets [25-28] profiling estrogen-regulated genes in MCF-7 cells were also employed for screening estrogen-regulated genes. A total of 403 genes were upregulated in E2-treated MCF-7 cells compared with the control cells. The overlap between the putative target genes of miR-26 and E2-upregulated genes yielded a set of 26 genes, which were considered as candidate target genes utilized by miR-26 to mediate estrogen-stimulated cellular effects.

To determine which of the 26 genes could be actually regulated by miR-26, RT-PCR analysis was performed to examine their expression with forced expression of miR-26b in MCF-7 or T47D cells. The mRNA levels of 10 genes (AGPAT5, AMMECR1, CHD1, ERLIN1, GREB1, HSPA8, KPNA2, MREG, NARG1 and PLOD2) significantly decreased following the forced expression of miR26b (Figure 3b; Figure S3 in Additional file 1). Moreover, we further verified that the expression of the 10 genes at the mRNA level was upregulated following estrogen treatment (Figure S4 in Additional file 1), suggesting that those 10 genes could be regulated by both estrogen and miR-26. 

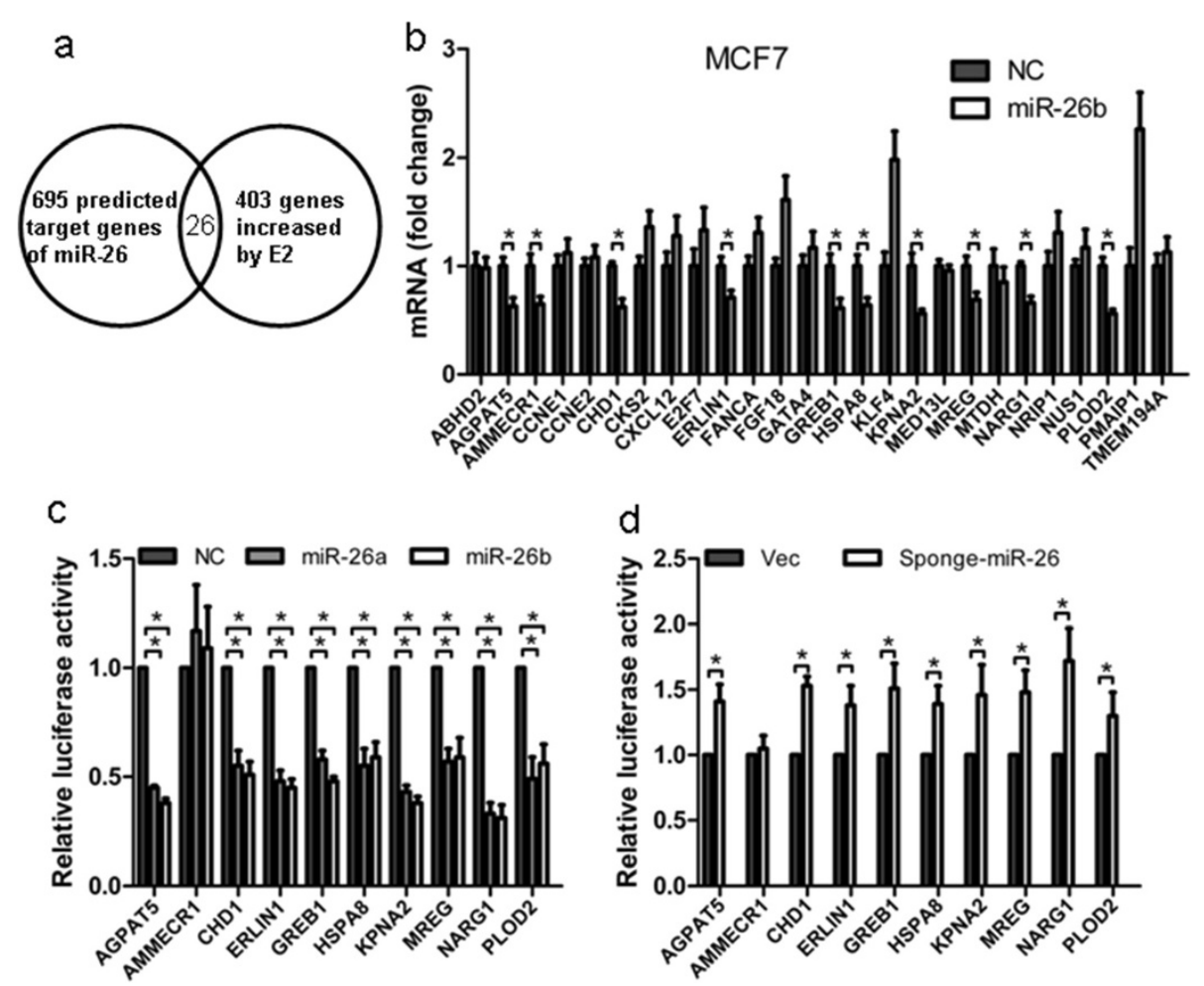

Figure 3 Regulation of gene expression by miR-26. (a) Venn diagram showing the number of genes identified by prediction methods compared with differential expression in 17ß-estradiol (E2)-treated MCF-7 cells. (b) Ectopic expression of miR-26b in MCF-7 cells decreased mRNA levels of the indicated 10 genes by quantitative real-time polymerase chain reaction. Glyceraldehyde 3-phosphate dehydrogenase was used as an internal control. (c) Luciferase reporter assays in T47D cells, with co-transfection of the wild-type $3^{\prime}$ utranslated region (UTR) and miRNA as indicated. (d) Luciferase reporter assays in T47D cells, with co-transfection of wild-type $3^{\prime}$ UTR and miRNA sponge as indicated. ${ }^{*} P<0.05$. ${ }^{*} P<0.01$.

We further cloned the 3' UTR of all 10 genes and generated fusions to a luciferase reporter gene. Forced expression of miR-26a or miR-26b mimics significantly reduced the activity of luciferase reporter gene fused to the 3' UTR of all the candidate target genes (except $A M M E C R 1$ ) by more than $40 \%$ (Figure 3c). These data suggest that miR-26a and miR-26b could directly target nine genes via their respective 3' UTR. Consistently, depletion of miR-26a/b by miR-26 sponge could increase the activity of luciferase reporter genes fused to the 3' UTR of the same cohort of nine genes (AGPAT5, CHD1, ERLIN1, GREB1, HSPA8, KPNA2, MREG, NARG1 and PLOD2) by more than $30 \%$ (Figure $3 \mathrm{~d}$ ). The activity of a luciferase reporter gene containing the AMMECR1 3' UTR exhibited minimal change upon depletion of endogenous miR-26 (Figure 3d).

\section{CHD1, GREB1 and KPNA2 as critical mediators of miR-26 elicited cell growth}

Given that miR-26 negatively regulated ER+ breast cancer cell proliferation, we wished to determine which of the identified targets of miR-26 actually mediated miR26-influenced cell growth. MCF-7 and T47D cells were thus transfected with siRNAs against these nine genes and the efficacy of siRNAs verified by RT-PCR (Figure S5 in Additional file 1). Interestingly silencing of CHD1, GREB1 or KPNA2 but not the remainder of the miR-26regulated target genes significantly decreased E2-promoted growth of MCF-7 and T47D cells (Figure 4). In addition, silencing of the other six genes did not significantly affect the growth of MCF-7 and T47D cells in the presence or absence of estrogen (Figure S6 in Additional file 1), suggesting that the regulation of AGPAT5, ERLIN1, HSPA8, MREG, NARG1 or PLOD2 by miR-26a and miR-26b may be used for other cellular functions in breast cancer cells.

CHD1, GREB1 and KPNA2 are the direct targets of miR-26 Using TargetScan, we located the potential binding sites for miR-26 at the 3' UTR of CHD1, GREB1 and KPNA2 and the respective mutants were further constructed (Figure 5a). We co-transfected luciferase reporter plasmids containing the $3^{\prime}$ UTR of each of the three genes with or without mutation and miR-26a mimics, miR-26b mimics or control oligonucleotides. Forced expression of miR-26a mimics or miR-26b mimics markedly reduced the activity of luciferase reporter genes fused to wildtype 3 ' UTRs by more than $40 \%$, but failed to affect the reporter activity when the 3' UTR was mutated (Figure 5b). 


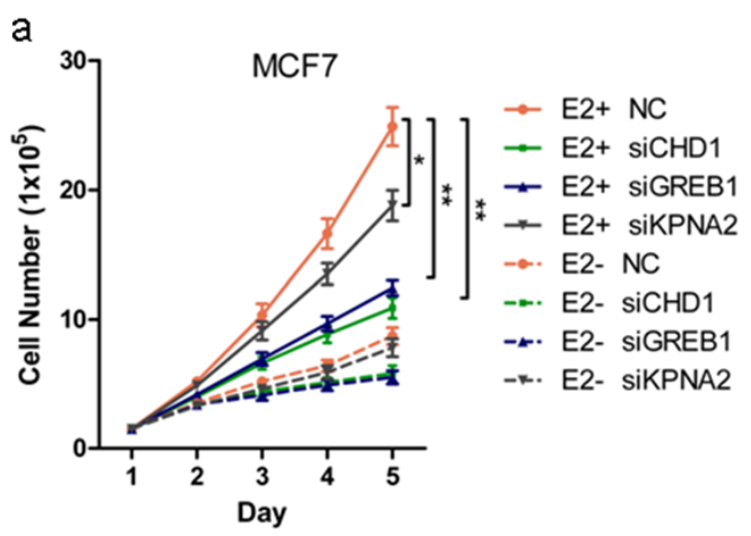

C

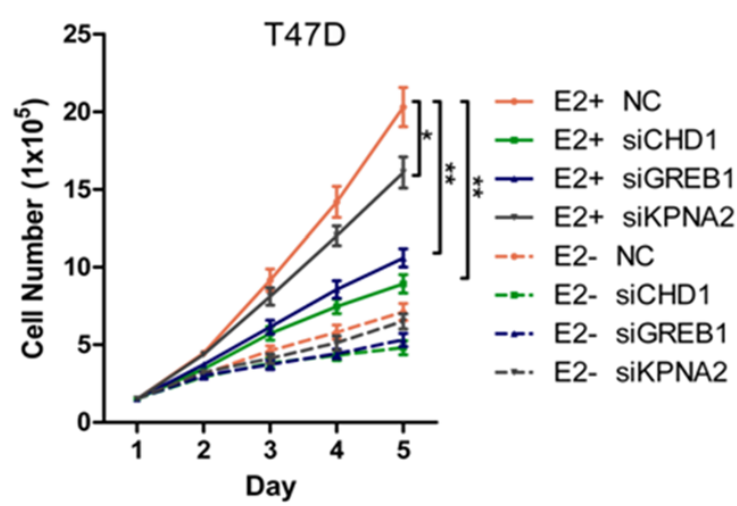

b

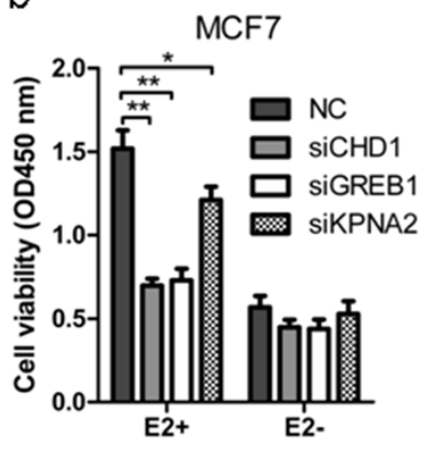

d

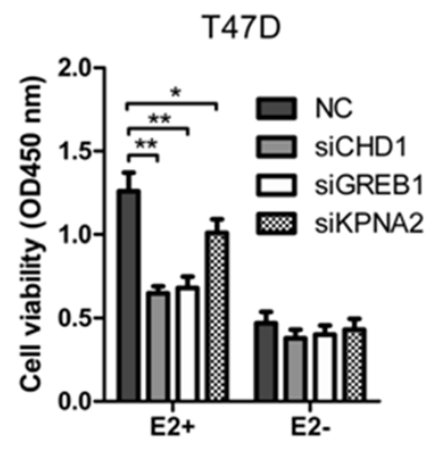

Figure 4 Small interfering RNA-mediated depletion of CHD1, GREB1 or KPNA2 expression recapitulates the tumor suppressive functions of miR-26. $(\mathbf{a}, \mathbf{c})$ MCF-7 or T47D cells deprived of estrogen for 2 days were infected with NC or small interfering RNA (siRNA) and 1 day later were seeded in six-well plates with or without $10 \mathrm{nmol} / \mathrm{l} 17 \beta$-estradiol (E2). At the indicated time points after transfection, cells were trypsinized and total cell numbers were counted using Trypan blue. (b, d) MCF-7 or T47D cells deprived of estrogen for 2 days were infected with NC or siRNA and 1 day later were seeded in 96-well plates with or without $10 \mathrm{nmol} / \mathrm{I}$ E2. At 72 hours after plating, the MTT assay was performed to determine the proliferation of MCF-7 and T47D cells. ${ }^{*} P<0.05 .{ }^{*} P<0.01$.

Consistently, miR-26 depletion by sponge produced a marked increase in the luciferase activity of the reporter plasmid containing the wild-type 3' UTRs, but not their mutants (Figure $5 \mathrm{c}$ ). miR-26 hence directly binds to the respective 3' UTR of CHD1, GREB1 or KPNA2 to regulate their expression. We further verified that forced expression of miR-26a mimics or miR-26b mimics significantly reduced the expression of CHD1, GREB1 and KPNA2 at the protein level in MCF-7 and T47D cells (Figure 5d). As expected, the expression of CHD1, GREB1 and KPNA2 protein was increased after forced expression of SpongemiR-26 in both MCF-7 and T47D cells (Figure 5e). Transfection of miR-26a or miR-26b mimics substantially abrogated estrogen-stimulated expression of CHD1, GREB1 and KPNA2, indicating that estrogen induced expression of CHD1, GREB1 and KPNA2 via miR-26a/b (Figure 5f,g). Immunohistochemical analysis of the tumors derived from MCF-7 cells with forced expression of miR-26 demonstrated lower expression of GREB1, CHD1 and KPNA2 compared with control tumors (Figure 2e).
CHD1, GREB1 and KPNA2 as mediators of cell growth promoted by miR-26 depletion

To further determine whether the expression of CHD1, GREB1 or KPNA2 was required for cellular events downstream of miR-26a/b, siRNAs for CHD1, GREB1 or KPNA2 were transfected into MCF-7/Vec, MCF-7/Sponge-miR-26, T47D/Vec and T47D/Sponge-miR-26 cells (Figure 6). The results showed that specific depletion of CHD1 or GREB1 or KPNA2 by siRNA significantly abrogated the enhanced growth of MCF-7 (Figure 6a,b) and T47D (Figure 6c,d) cells consequent to miR-26 depletion. The expression of CHD1, GREB1 and KPNA2 is hence required to promote cell growth consequent to miR-26 depletion.

\section{Estrogen-induced c-MYC expression is necessary for the} repression of miR-26a and miR-26b expression

c-MYC was previously reported to regulate the expression of many miRNAs, including miR-26a and miR-26b $[21,29,30]$. To explore whether c-MYC was required for estrogen-simulated repression of miR-26a/b in MCF-7 


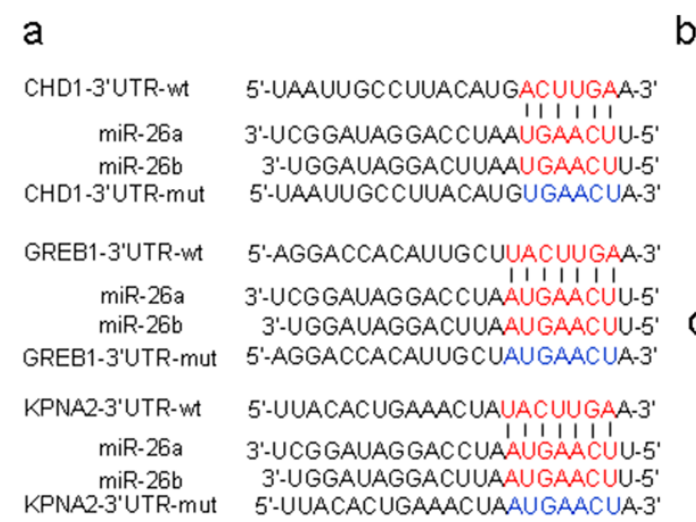

b

d

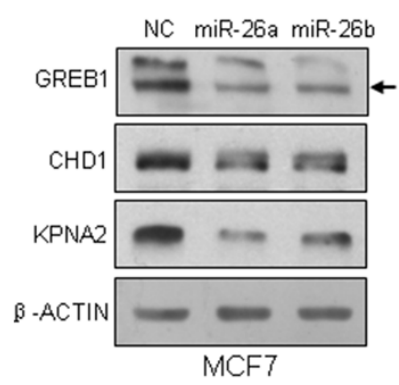

f

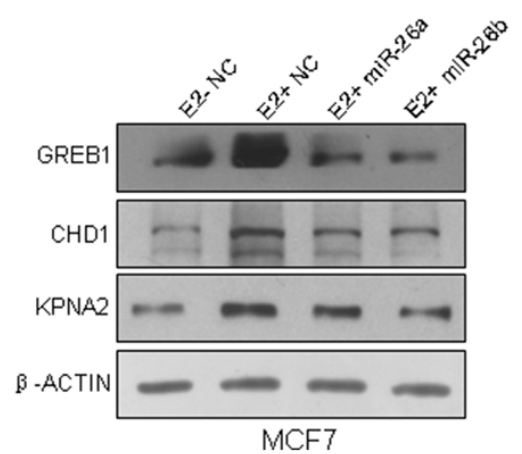

e
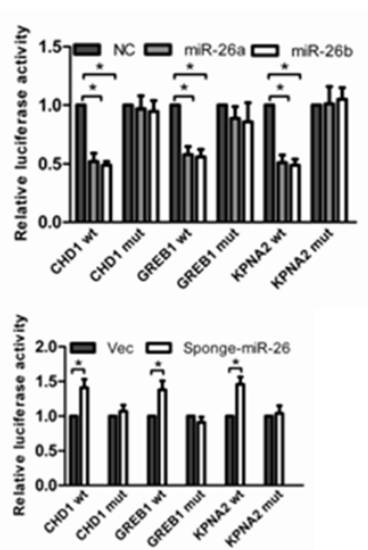
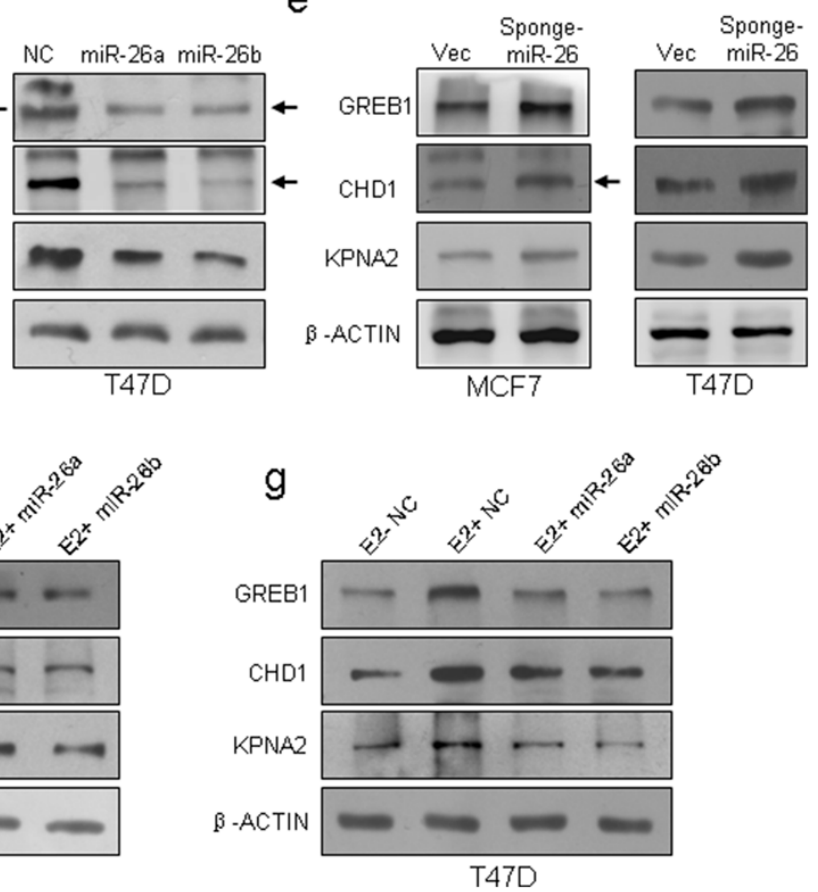

Figure 5 miR-26 directly targets CHD1, GREB1 and KPNA2 genes. (a) Putative miR-26-binding sequences in the 3' untranslated region (UTR) of CHD1, GREB1 and KPNA2 mRNA. Mutations were generated on the CHD1, GREB1 and KPNA2 3' UTR sequence in the complementary site for the seed region of miR-26. (b) Luciferase reporter assays in T47D cells, with co-transfection of wild-type (wt) or mutant (mut) 3' UTR and microRNA (miRNA) as indicated. (c) Luciferase reporter assays in T47D cells, with co-transfection of wt or mut 3' UTR and miRNA sponge as indicated. (d) Forced expression of miR-26a or miR-26b in MCF-7 and T47D cells decreased protein levels of CHD1, GREB1 and KPNA2 by western blot analysis. (d, e) After forced expression or depletion of miR-26, the expression of CHD1, GREB1 and KPNA2 protein were analyzed by western blot assay. (f, $\mathbf{g})$ Western blotting analysis of the expression of CHD1, GREB1 and KPNA2 protein in 17ß-estradiol (E2)-treated MCF-7 and T47D cells transfected with the indicated miRNA molecules. ${ }^{*} P<0.01$.

and T47D cells, control vector or c-MYC-expressing plasmids were transfected in both cell lines. As expected, forced expression of c-MYC resulted in the reduced expression of miR-26a and miR-26b in both MCF-7 and T47D cells (Figure 7a,b,c). c-MYC has been reported as an estrogen-responsive gene and is a positive regulator of estrogen-stimulated breast cancer cell growth [31-33]. We therefore next determined whether c-MYC was involved in estrogenic suppression of miR-26a/b. We first verified the efficacy of the c-MYC-specific siRNA duplex in the presence or absence of estrogen stimulation in both MCF-7 and T47D cells (Figure 7d). Abrogation of MYC expression by siRNA resulted in a substantial increased expression of estrogen-stimulated miR-26a and miR-26b (Figure 7e,f), indicating that c-MYC was a mediator of estrogenic repression of miR-26a/b expression. We next investigated whether c-MYC expression was required for estrogen-stimulated expression of GREB1, 

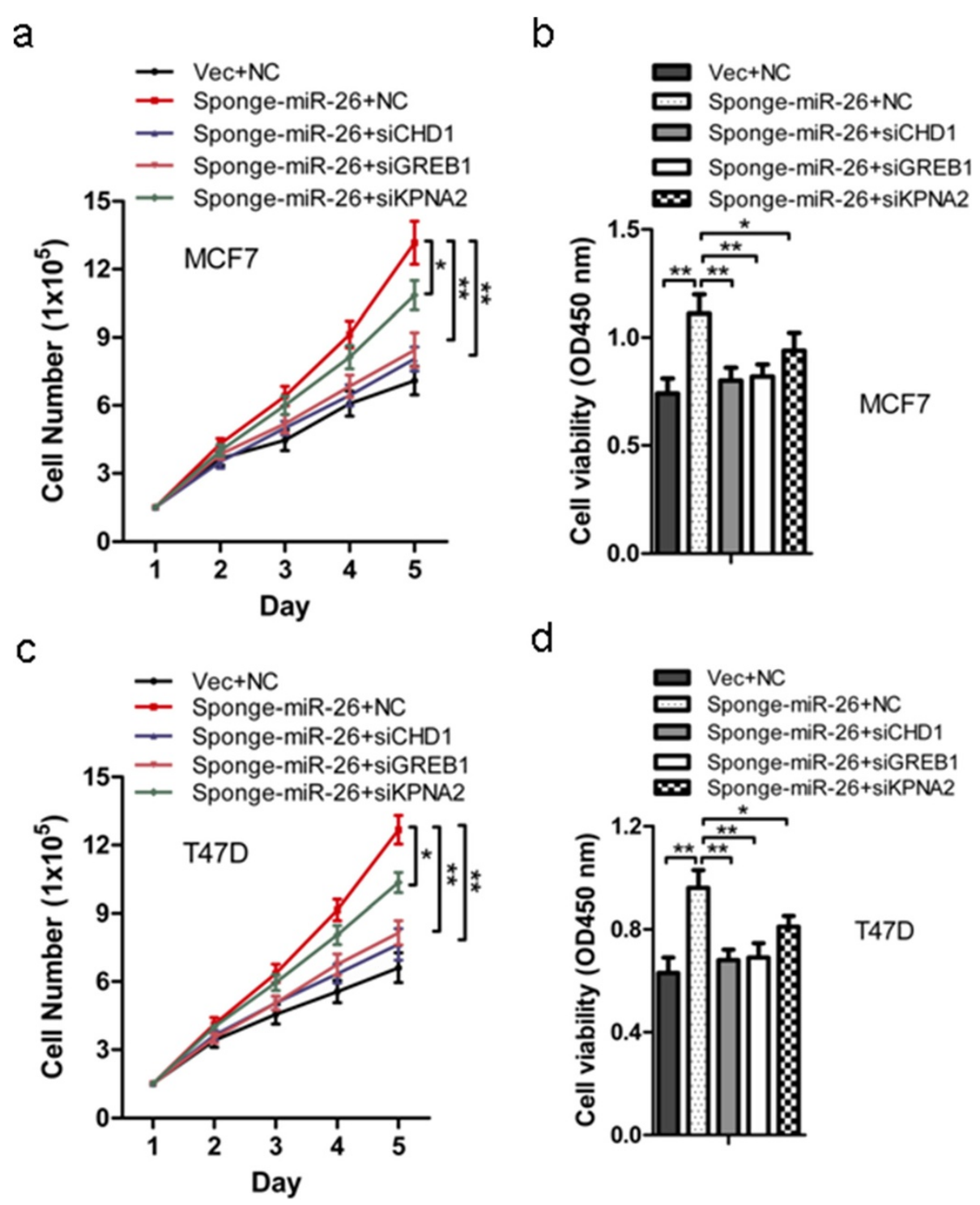

d

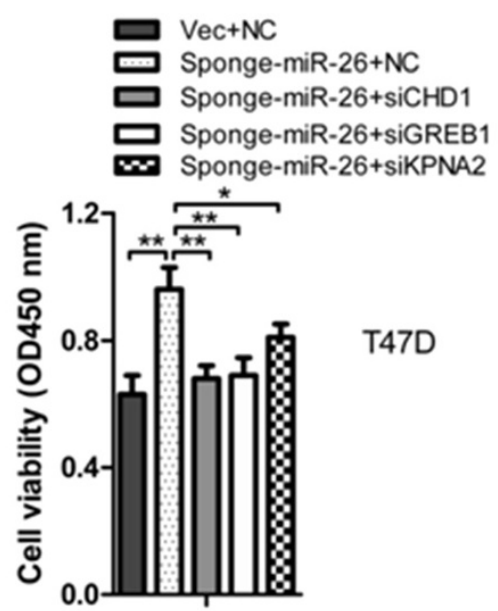

Figure 6 CHD1, GREB1 or KPNA2 small interfering RNA partially mimics the effect of Sponge-miR-26 on MCF-7 and T47D cells. (a, c) MCF-7-Vec and MCF-7-Sponge-miR-26 cells deprived of estrogen for 2 days were transfected with NC or small interfering (siRNA) and 1 day later were seeded in six-well plates without $10 \mathrm{nmol} / \mathrm{I} 17 \beta$-estradiol (E2). At the indicated time points after transfected NC or siRNA, MCF-7-Vec, MCF-7-Sponge-miR-26, T47D-Vec and T47D-Sponge-miR-26 cells were trypsinized and total cell numbers were counted using Trypan blue. (b, d) MCF-7-Vec and MCF-7-Sponge-miR-26 cells deprived of estrogen for 2 days were transfected with NC or siRNA and 1 day later were seeded in 96-well plates without $10 \mathrm{nmol} / \mathrm{I}$ E2. At 96 hours after plating, the MTT assay was performed to determine the proliferation of MCF-7-Vec, MCF-7-Sponge-miR-26, T47D-Vec and T47D-Sponge-miR-26 cells. ${ }^{*} P<0.05 .{ }^{* *} P<0.01$.

CHD1 and KPNA2. Remarkably, depletion of MYC by siRNA significantly diminished estrogen-stimulated expression of GREB1, CHD1 and KPNA2 in both MCF-7 and T47D cells (Figure 7g,h).

miR-26a and miR-26b expression are decreased in breast cancer

We compared the levels of miR-26a/b in 20 samples of normal breast tissue and $30 \mathrm{ER}+$ breast cancer specimens by stem-loop qRT-PCR. Expression of miR-26a and miR$26 \mathrm{~b}$ was reduced in breast cancer specimens $(P<0.05)$ compared with normal tissues (Figure 8a,b). We further evaluated the expression levels of CHD1, GREB1 and KPNA2 mRNA in these breast cancer specimens by qRTPCR. The results showed that the average expression levels of CHD1 and KPNA2 were significantly higher in breast cancers $(P<0.05)$ than in normal breast tissues (Figure $8 \mathrm{c}, \mathrm{d}$ ). However, the average expression level of 


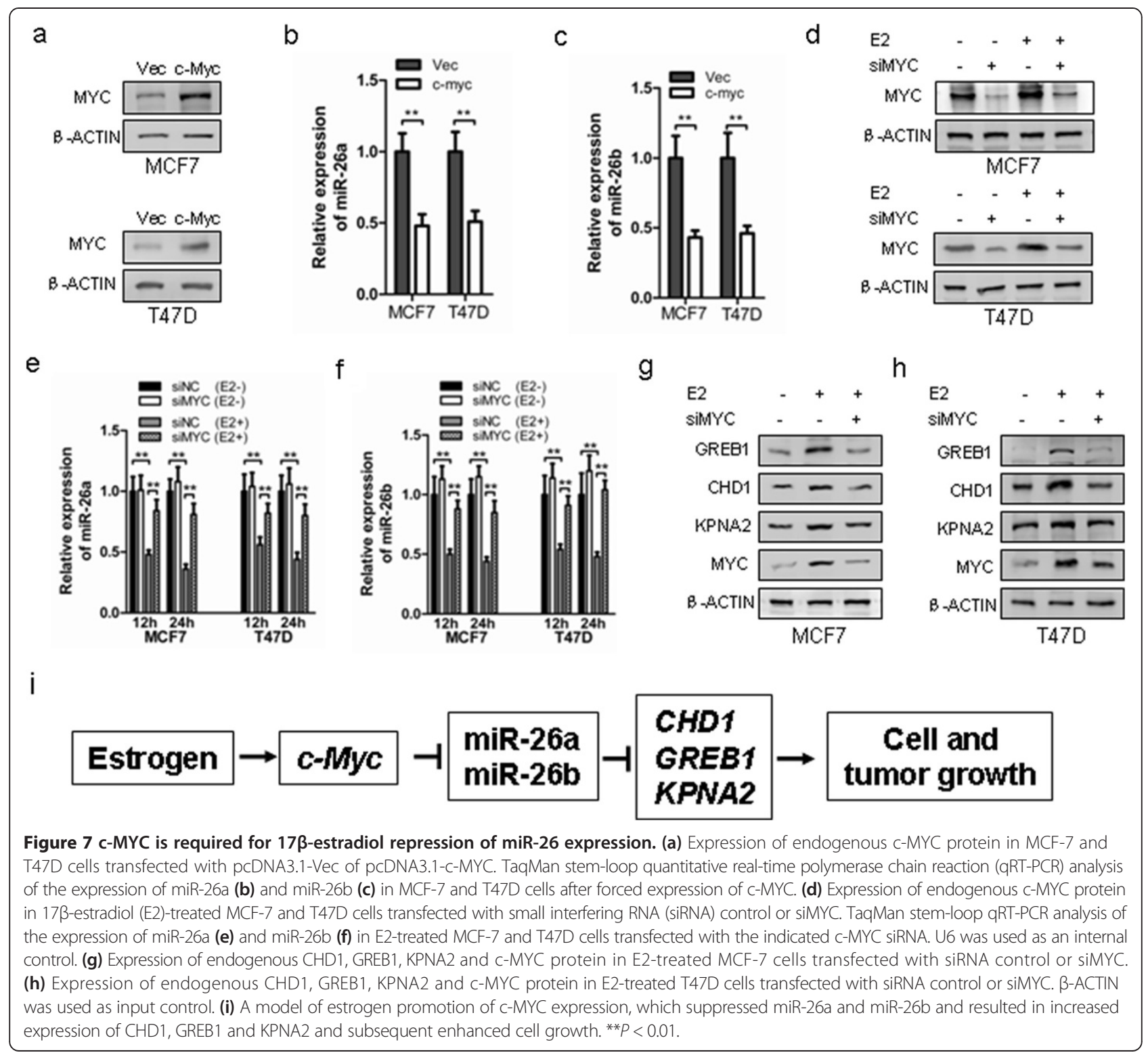

GREB1 was slightly lower in breast cancers $(P>0.05)$ than in normal breast tissues (Figure S7 in Additional file 1). We subsequently correlated CHD1, GREB1 and KPNA2 with miR-26 expression in these specimens. When CHD1 mRNA levels were plotted against miR-26a and miR26b expression, significant inverse correlations were observed $(P<0.05$; Figure $8 \mathrm{e}, \mathrm{f})$. When KPNA2 mRNA levels were plotted against miR-26b expression, significant inverse correlations were observed ( $P<0.05$; Figure $8 \mathrm{~h}$ ). However, when the KPNA2 mRNA level was plotted against miR-26a expression $(P>0.05$, Figure $8 g)$ or when the GREB1 mRNA level was plotted against miR-26 expression $(P>0.05$; Figure S7 in Additional file 1$)$, there were no significant inverse correlations.

\section{Discussion}

Breast cancer is one of the most prevalent causes of cancerrelated death for women worldwide. Estrogens play an important role in breast cancer [2,3]. Estrogen acts through ER-alpha and ER-beta, and blockade of estrogen signaling with anti-estrogens is an effective treatment for the majority of patients with ER-alpha-positive breast cancer. However, many ER+ breast cancer patients that initially respond to anti-estrogen therapy develop tumor recurrence [4]. An improved understanding of the molecular basis of estrogen treatment and the development of new strategies to increase the efficacy of anti-estrogens are required.

miRNAs have been demonstrated to play important roles in breast cancer development [5,6]. miR-26a or 

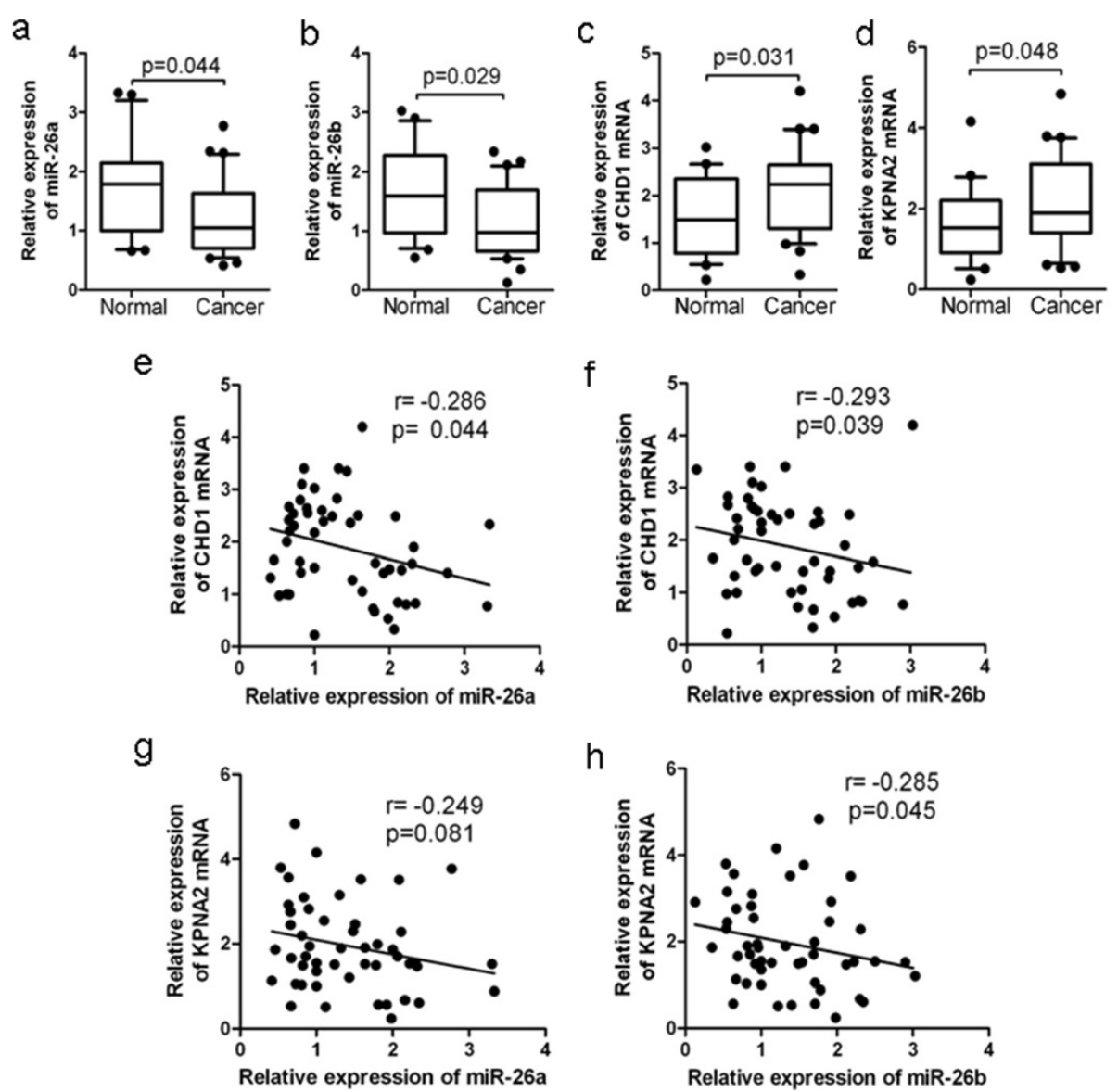

Figure 8 miR-26 was downregulated in breast cancer and inversely correlated with CHD1 and KPNA2 levels. (a, b) Relative expression levels of miR-26 in human breast specimens. MicroRNA (miRNA) levels were measured by TaqMan stem-loop quantitative real-time polymerase chain reaction. U6 was used as an internal control. (c, d) Relative expression levels of CHD1 and KPNA2 mRNA in breast clinical specimens. CHD1 and KPNA2 abundance was normalized to glyceraldehyde 3-phosphate dehydrogenase. $(\mathbf{e}, \mathbf{f}, \mathbf{g}, \mathbf{h})$ A statistically inverse correlation between miR-26 and CHD1 and KPNA2 mRNA levels in human breast specimens (Spearman's correlation analysis).

miR-26b were reported to be downregulated in breast cancer and they were therefore regarded as tumor suppressor miRNAs $[18,19,23,34]$. Estrogen treatment resulted in reduced expression of miR-26a in an ER-dependent manner $[18,19]$. miR-26a has also been reported to directly suppress progesterone receptor expression through binding to the progesterone receptor 3' UTR. However, whether progesterone receptor actually mediated miR-26a repressionpromoted cell growth in response to estrogen stimulation was not defined in this study [18]. Herein, we report that miR-26a and miR-26b were downregulated following estrogen treatment in ER+ human breast cancer cells. To date, experimentally validated miR-26 targets contain many oncogenes, including EZH2 [30], CCND2 [21], CCNE2 [21], $M T D H$ [34] and SLC7A11 [35]. However, none of these were reported to be estrogen responsive.

To determine how the altered expression of miR-26 may mediate estrogenic effects, we first screened estrogen- responsive genes that were also predicted to be miR-26 target genes by both bioinformatics and RT-PCR analysis. GREB1 and nine other genes (AGPAT5, AMMECR1, CHD1, ERLIN1, HSPA8, KPNA2, MREG, NARG1 and $P L O D 2)$ were subsequently identified. Further verification by luciferase reporter assay identified nine other genes (AGPAT5, CHD1, ERLIN1, GREB1, HSPA8, KPNA2, MREG, NARG1 and PLOD2) that were directly targeted by miR-26 via their 3' UTR. Functional screening suggested that only three estrogen-regulated miR-26 target genes (CHD1, GREB1 and KPNA2) were involved in the regulation of estrogen-promoted cell proliferation. We thus identified CHD1, GREB1 and KPNA2 as novel functional targets of miR-26. The expression of miR-26a and miR-26b in human breast cancer cells suppressed cell growth, at least partly through repression of CHD1, GREB1 and KPNA2. Consistently, depletion of CHD1, GREB1 or KPNA2 produced cell growth inhibition similar 
to the phenotypes induced by miR-26a or miR-26b restoration. These data verified previous findings, in which the depletion of GREB1 suppressed MCF-7 cell proliferation [25]. However, we further determined that increased expression of CHD1, GREB1 and KPNA2 following estrogen treatment was partially due to the decreased expression of miR-26a and miR-26b. Moreover, we determined that CHD1 and KPNA2 were necessary for estrogen-stimulated proliferation of breast cancer cells.

c-MYC, as a well-known estrogen-responsive gene, has been shown to mediate the proliferative effects of estrogen in ER+ breast cancer cells [36]. Antisense oligonucleotides directed against c-MYC inhibit estrogen-induced cell proliferation in a manner similar to that of anti-estrogens [37]. In this study, we examined the possibility of the estrogenic effects of c-MYC mediating a c-MYC-regulated miRNA network. c-MYC has been reported to suppress the expression of many miRNAs, including miR-26a and $26 \mathrm{~b}[21,29,30]$. However, it was unclear whether c-MYC is involved in estrogenic repression of miR-26a and miR-26b expression. Our observations imply that c-MYC is necessary for inhibition of miR-26a and miR-26b expression produced by estrogen. The results further suggest that aberrant c-MYC expression, which is frequently observed in human breast cancers [38], can contribute to the estrogenic effect by alteration of miR-26a and miR-26b expression. Our results have thus identified a novel pathway by which estrogen utilizes c-MYC for suppression of miR$26 \mathrm{a} / \mathrm{b}$ to promote the expression of CHD1, GREB1 and KPNA2 (Figure 7i).

This study systematically investigated the functionality and mechanism of miR-26a and miR-26b in estrogenpromoted ER+ breast cancer cell proliferation. GREB1, CHD1 and KPNA2 were identified as novel targets of $\mathrm{miR}-26 \mathrm{a} / \mathrm{b}$ and were demonstrated to be necessary for estrogen-promoted ER+ breast cancer cell proliferation. Further, we demonstrated that estrogen-stimulated c-MYC expression was both sufficient and necessary for the diminished expression of miR-26a and miR-26b. These findings will facilitate a better understanding of the molecular pathogenesis of breast cancer and suggest that mimics of miR-26a and miR-26b may be considered as a novel strategy for breast cancer therapy.

\section{Conclusions}

Estrogen signaling is pivotal in the progression of ER+ breast cancer. An improved understanding of the molecular basis of estrogen action and the development of new strategies to improve the efficacy of anti-estrogens are required. We have therefore identified a novel estrogen/ $\mathrm{MYC} / \mathrm{miR}-26$ axis that mediated estrogen stimulated cell growth via CHD1, GREB1 and KPNA2 and suggest that upregulation of miR-26a and miR-26b may be considered as novel strategy for breast cancer therapy.

\section{Additional file}

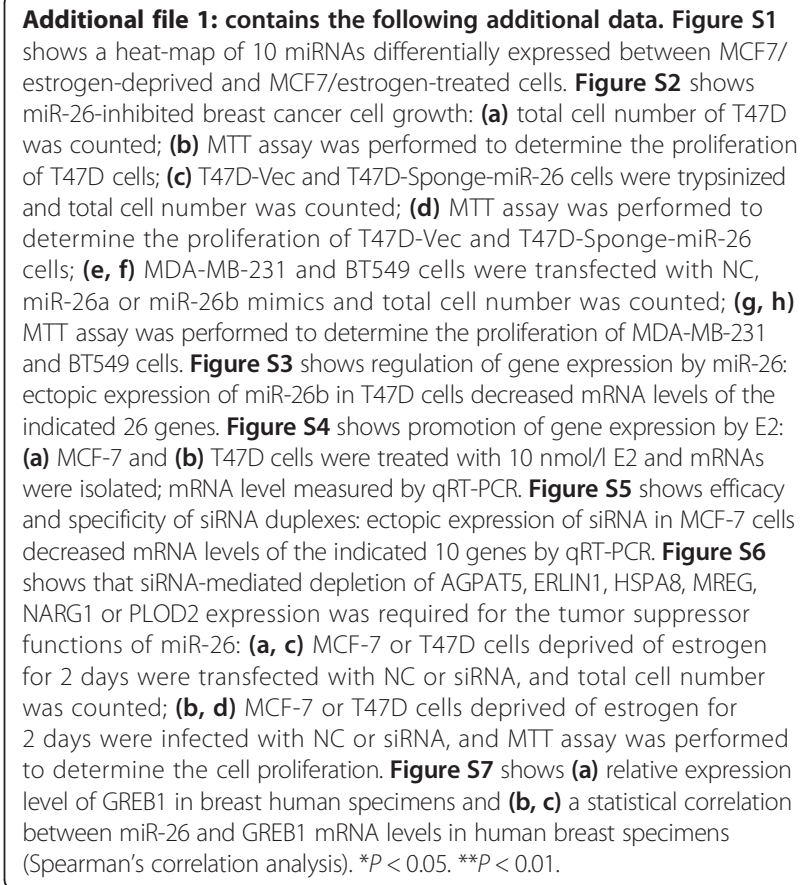

\section{Abbreviations}

E2: 17ß-estradiol; ER: estrogen receptor; miRNA: microRNA; PCR: polymerase chain reaction; RT: real-time; siRNA: small interfering RNA; UTR: untranslated region.

\section{Competing interests}

The authors declare that they have no competing interests.

\section{Authors' contributions}

ST maintained all of the cell cultures, designed the siRNA experiment, ran qRT-PCR and western blots, performed the in vivo study, was involved in the design of the study and critically revised the manuscript. KD provided all of the plasmids used in the study, performed the siRNA experiment, ran QRT-PCR and western blots, performed the luciferase assays, participated in the design of the study and critically revised the manuscript. RL and WZ performed immunohistochemistry assays, were involved in the RNA and protein study, and participated in the manuscript writing. GL participated in the animal study and critically revised the manuscript. $\mathrm{XK}$ and $\mathrm{PQ}$ participated in data collection and were involved in the manuscript writing. PEL participated in data analysis and provided critical review of the manuscript. TZ conceived of the ideas of the manuscript, wrote the manuscript. All authors approved the final manuscript for publication.

\section{Acknowledgements}

This work was supported by the National Key Scientific Program of China (2012CB934002, 2010CB912804), the National Natural Science Foundation of China $(81272925,31201022)$ and the Cancer Science Institute of Singapore through grants from the Ministry of Education and the National Research Foundation of Singapore.

\section{Author details}

${ }^{1}$ Laboratory of Molecular Tumor Pathology, School of Life Sciences, University of Science and Technology of China, Hefei 230027, China. ${ }^{2}$ Cancer Science Institute of Singapore, National University of Singapore, Centre for Translational Medicine MD6, \#11-01 K, 14 Medical Drive, Singapore 117599, Singapore. ${ }^{3}$ National Cancer Institute of Singapore, National University Health System, Singapore, Singapore. ${ }^{4}$ Hefei National Laboratory for Physical Sciences at Microscale and School of Life Sciences, University of Science and Technology of China, Hefei, Anhui 230027, People's Republic of China. 
Received: 13 September 2013 Accepted: 28 March 2014 Published: 15 April 2014

\section{References}

1. Vargo-Gogola T, Rosen JM: Modelling breast cancer: one size does not fit all. Nat Rev Cancer 2007, 7:659-672.

2. Yager JD, Davidson NE: Estrogen carcinogenesis in breast cancer. N Engl J Med 2006, 354:270-282.

3. Tyson JJ, Baumann WT, Chen C, Verdugo A, Tavassoly I, Wang Y, Weiner LM, Clarke R: Dynamic modelling of oestrogen signalling and cell fate in breast cancer cells. Nat Rev Cancer 2011, 11:523-532.

4. Musgrove EA, Sutherland RL: Biological determinants of endocrine resistance in breast cancer. Nat Rev Cancer 2009, 9:631-643.

5. Bartel DP: MicroRNAs: target recognition and regulatory functions. Cell 2009, 136:215-233.

6. Esquela-Kerscher A, Slack FJ: Oncomirs - microRNAs with a role in cancer. Nat Rev Cancer 2006, 6:259-269.

7. Kasinski AL, Slack FJ: Epigenetics and genetics. MicroRNAs en route to the clinic: progress in validating and targeting microRNAs for cancer therapy. Nat Rev Cancer 2011, 11:849-864.

8. Selbach M, Schwanhausser B, Thierfelder N, Fang Z, Khanin R, Rajewsky N: Widespread changes in protein synthesis induced by microRNAs. Nature 2008, 455:58-63.

9. Baek D, Villen J, Shin C, Camargo FD, Gygi SP, Bartel DP: The impact of microRNAs on protein output. Nature 2008, 455:64-71.

10. Iorio MV, Ferracin M, Liu CG, Veronese A, Spizzo R, Sabbioni S, Magri E, Pedriali M, Fabbri M, Campiglio M, Ménard S, Palazzo JP, Rosenberg A, Musiani P, Volinia S, Nenci I, Calin GA, Querzoli P, Negrini M, Croce CM: MicroRNA gene expression deregulation in human breast cancer. Cancer Res 2005, 65:7065-7070.

11. Sempere LF, Christensen M, Silahtaroglu A, Bak M, Heath CV, Schwartz G, Wells W, Kauppinen S, Cole CN: Altered MicroRNA expression confined to specific epithelial cell subpopulations in breast cancer. Cancer Res 2007, 67:11612-11620.

12. Yu F, Yao H, Zhu P, Zhang X, Pan Q, Gong C, Huang Y, Hu X, Su F, Lieberman J: Song E: let-7 regulates self renewal and tumorigenicity of breast cancer cells. Cell 2007, 131:1109-1123.

13. Frankel LB, Christoffersen NR, Jacobsen A, Lindow M, Krogh A, Lund AH: Programmed cell death 4 (PDCD4) is an important functional target of the microRNA miR-21 in breast cancer cells. J Biol Chem 2008, 283:1026-1033.

14. Scott GK, Goga A, Bhaumik D, Berger CE, Sullivan CS, Benz CC: Coordinate suppression of ERBB2 and ERBB3 by enforced expression of micro-RNA miR-125a or miR-125b. J Biol Chem 2007, 282:1479-1486.

15. Miller TE, Ghoshal K, Ramaswamy B, Roy S, Datta J, Shapiro CL, Jacob S, Majumder S: MicroRNA-221/222 confers tamoxifen resistance in breast cancer by targeting p27Kip1. J Biol Chem 2008, 283:29897-29903.

16. Zhao JJ, Lin J, Yang H, Kong W, He L, Ma X, Coppola D, Cheng JQ: MicroRNA-221/222 negatively regulates estrogen receptor alpha and is associated with tamoxifen resistance in breast cancer. J Biol Chem 2008, 283:31079-31086

17. Qian P, Zuo Z, Wu Z, Meng X, Li G, Wu Z, Zhang W, Tan S, Pandey V, Yao Y, Wang P, Zhao L, Wang J, Wu Q, Song E, Lobie PE, Yin Z, Zhu T: Pivotal role of reduced let-7 $\mathrm{g}$ expression in breast cancer invasion and metastasis. Cancer Res 2011, 71:6463-6474.

18. Maillot $G$, Lacroix-Triki M, Pierredon $S$, Gratadou L, Schmidt $S$, Bénès V, Roché H, Dalenc F, Auboeuf D, Millevoi S, Vagner S: Widespread estrogen-dependent repression of micrornas involved in breast tumor cell growth. Cancer Res 2009, 69:8332-8340.

19. Bhat-Nakshatri P, Wang G, Collins NR, Thomson MJ, Geistlinger TR, Carroll JS, Brown M, Hammond S, Srour EF, Liu Y, Nakshatri H: Estradiol-regulated microRNAs control estradiol response in breast cancer cells. Nucleic Acids Res 2009, 37:4850-4861.

20. Castellano L, Giamas G, Jacob J, Coombes RC, Lucchesi W, Thiruchelvam P, Barton G, Jiao LR, Wait R, Waxman J, Hannon GJ, Stebbing J: The estrogen receptor-alpha-induced microRNA signature regulates itself and its transcriptional response. Proc Natl Acad Sci U S A 2009, 106:15732-15737.

21. Kota J, Chivukula RR, O'Donnell KA, Wentzel EA, Montgomery CL, Hwang HW, Chang TC, Vivekanandan P, Torbenson M, Clark KR, Mendell JR, Mendell $J$ T: Therapeutic microRNA delivery suppresses tumorigenesis in a murine liver cancer model. Cell 2009, 137:1005-1017.
22. Gentner B, Schira G, Giustacchini A, Amendola M, Brown BD, Ponzoni M, Naldini L: Stable knockdown of microRNA in vivo by lentiviral vectors. Nat Methods 2009, 6:63-66.

23. Ebert MS, Neilson JR, Sharp PA: MicroRNA sponges: competitive inhibitors of small RNAs in mammalian cells. Nat Methods 2007, 4:721-726.

24. Tan S, Li R, Ding K, Lobie PE: Zhu T: miR-198 inhibits migration and invasion of hepatocellular carcinoma cells by targeting the HGF/c-MET pathway. FEBS Lett 2011, 585:2229-2234.

25. Rae JM, Johnson MD, Scheys JO, Cordero KE, Larios JM, Lippman ME: GREB 1 is a critical regulator of hormone dependent breast cancer growth. Breast Cancer Res Treat 2005, 92:141-149.

26. Lin CY, Vega VB, Thomsen JS, Zhang T, Kong SL, Xie M, Chiu KP, Lipovich L, Barnett DH, Stossi F, Yeo A, George J, Kuznetsov VA, Lee YK, Charn TH, Palanisamy N, Miller LD, Cheung E, Katzenellenbogen BS, Ruan Y, Bourque G, Wei CL, Liu ET: Whole-genome cartography of estrogen receptor alpha binding sites. PLOS Gen 2007, 3:e87.

27. Ochsner SA, Steffen DL, Hilsenbeck SG, Chen ES, Watkins C, McKenna NJ: GEMS (Gene Expression MetaSignatures), a Web resource for querying meta-analysis of expression microarray datasets: $17 \beta$-estradiol in MCF-7 cells. Cancer Res 2009, 69:23-26.

28. Frasor J, Chang EC, Komm B, Lin CY, Vega VB, Liu ET, Miller LD, Smeds J, Bergh J, Katzenellenbogen BS: Gene expression preferentially regulated by tamoxifen in breast cancer cells and correlations with clinical outcome. Cancer Res 2006, 66:7334-7340.

29. Chang TC, Yu D, Lee YS, Wentzel EA, Arking DE, West KM, Dang CV, Thomas-Tikhonenko A, Mendell JT: Widespread microRNA repression by Myc contributes to tumorigenesis. Nat Gen 2008, 40:43-50.

30. Sander S, Bullinger L, Klapproth K, Fiedler K, Kestler HA, Barth TF, Moller P, Stilgenbauer S, Pollack JR, Wirth T: MYC stimulates EZH2 expression by repression of its negative regulator miR-26a. Blood 2008, 112:4202-4212.

31. Dubik D, Dembinski TC, Shiu RP: Stimulation of c-myc oncogene expression associated with estrogen-induced proliferation of human breast cancer cells. Cancer Res 1987, 47:6517-6521.

32. Santos GF, Scott GK, Lee WM, Liu E, Benz C: Estrogen-induced post-transcriptional modulation of c-myc proto-oncogene expression in human breast cancer cells. J Biol Chem 1988, 263:9565-9568.

33. Dubik D, Shiu RP: Transcriptional regulation of c-myc oncogene expression by estrogen in hormone-responsive human breast cancer cells. $J$ Biol Chem 1988, 263:12705-12708.

34. Zhang B, Liu XX, He JR, Zhou CX, Guo M, He M, Li MF, Chen GQ, Zhao Q: Pathologically decreased miR-26a antagonizes apoptosis and facilitates carcinogenesis by targeting MTDH and EZH2 in breast cancer. Carcinogenesis 2011, 32:2-9.

35. Liu XX, Li XJ, Zhang B, Liang YJ, Zhou CX, Cao DX, He M, Chen GQ, He JR, Zhao Q: MicroRNA-26b is underexpressed in human breast cancer and induces cell apoptosis by targeting SLC7A11. FEBS Lett 2011, 585:1363-1367.

36. Mukherjee S: Conrad SE: c-Myc suppresses p21WAF1/CIP1 expression during estrogen signaling and antiestrogen resistance in human breast cancer cells. J Biol Chem 2005, 280:17617-17625.

37. Carroll JS, Swarbrick A, Musgrove EA, Sutherland RL: Mechanisms of growth arrest by c-myc antisense oligonucleotides in MCF-7 breast cancer cells: implications for the antiproliferative effects of antiestrogens. Cancer Res 2002, 62:3126-3131.

38. Xu J, Chen Y, Olopade OI: MYC and breast cancer. Genes Cancer 2010, 1:629-640.

\section{doi:10.1186/bcr3644}

Cite this article as: Tan et al.: Identification of miR-26 as a key mediator of estrogen stimulated cell proliferation by targeting CHD1, GREB1 and KPNA2. Breast Cancer Research 2014 16:R40. 